\title{
Ranking and Clustering Australian University Research Performance, $1998-2002^{*}$
}

Revised 16 August 2005

\author{
ABBAS VALADKHANI ${ }^{\mathrm{a},{ }^{*} 1}$, ANDREW WORTHINGTON ${ }^{\mathrm{b}}$ \\ ${ }^{\mathrm{a}}$ School of Economics and Information Systems, University of Wollongong, Wollongong, NSW, Australia \\ ${ }^{b}$ School of Accounting and Finance, University of Wollongong, Wollongong, NSW, Australia
}

\begin{abstract}
This paper clusters and ranks the research performance of thirty-six Australian universities over the period 1998-2002. Research performance is measured according to audited numbers of PhD completions, publications and grants (in accordance with rules established by the Department of Education, Science and Training) and analysed in both total and per academic staff terms. Hierarchical cluster analysis supports a binary division between fifteen higher and twenty-two lower-performing universities, with the specification in per academic staff terms identifying the self-designated research intensive 'Group of Seven' (Go7) universities, plus several others in the better-performing group. Factor analysis indicates that the top-three research performers are the Universities of Melbourne, Sydney and Queensland in terms of total research performance and the Universities of Melbourne, Adelaide and Western Australia in per academic staff terms.
\end{abstract}

JEL classification: Higher education, Hierarchical cluster analysis, Research performance, Factor analysis

Keywords: A11; A19; C63; I29

\section{Introduction}

It is well-recognised that Australian universities play a vital role in national research and the scholarship of research, partially justifying sizeable Commonwealth government funding. But for some decades, such funding has been administered independently of any specific assessment of research performance. Between 1965 and 1988, for example, a binary divide existed in the higher education sector whereby the smaller number of research-orientated 'universities' were automatically funded at a higher level than the larger number of teaching-orientated 'colleges of advanced education' and 'institutes of technology'. For the most part, such funding was more concerned with this division and institutional size and course mix, rather than any attempt to recognise and reward research.

However, from 1989 a series of policy changes, collectively known as the 'Dawkins reforms', created a Unified National System, in so doing removing the funding division between universities and non-universities. Within this system, since the 1990s Commonwealth research funding has been directed through three main channels. First, support for research training is provided through operating grants made on the basis of enrolments and disciplines, as well as in

\footnotetext{
* We wish to acknowledge Ian Dobson and an anonymous referee whose constructive inputs and comments considerably improved an earlier version of this article. The usual caveat applies.

${ }^{1}$ Corresponding author: tel +61 24221 4022; fax +61 24221 3725; email abbas@uow.edu.au
} 
the form of Australian Postgraduate Research Awards (APRA) scholarships for postgraduate research and exemptions for domestic students from the requirement to pay fees (in the form of HECS, the Higher Education Contribution Scheme). Second, funding in the form of a Research Quantum is allocated on the basis of a composite index to support university research and research-training more generally, taking into account both research inputs (private research and special government research funding) and research outputs (publications and postgraduate completions). Finally, program-specific funding is also allocated, encompassing, amongst other things, Australian Research Council (ARC) awards for projects (both wholly and industry-linked) and fellowships. But despite the apparent dissimilarity of these channels, all are allocated, at least indirectly, on the basis of an institution's research performance, partially facilitated by the Commonwealth's Department of Education, Science and Training (DEST) monitoring and assessment of research output ${ }^{2}$.

Problematically, at least for some institutions, there are currently proposals by the Commonwealth government to adopt a trinary system of classification with universities categorised as 'research intensive', 'teaching and research' or 'teaching only'. And not unexpectedly, this reclassification is generally thought to be associated with a move away from the current unitary system of performance-based funding. However, the means by which such a classification is to be obtained is subject to some conjecture, and there are concerns, especially by newer universities, that it would fall more or less along the lines of the older binary divide, despite argued gains in research performance in the interregnum. In this manner, the larger, more established universities (comprising the Group of Eight) would be automatically classified as research intensive, with the remaining universities (comprising the Innovative Research Universities Australia, the Australian Technology Network, New Generation Universities and Ungrouped Universities) taking up the lesser role, funding and status of 'research' and 'teaching' or (worse still) ‘teaching only’ universities.

Unfortunately, there has been very little quantitative work on the ranking and clustering of Australian university research performance that would provide guidance on these proposed policy changes. DEST (1998), for example, classified Australian universities on a wide range of research and teaching characteristics from 1996/1997 using cluster analysis. More than twenty different indicators were used to operationalise six measures of size, overseas orientation, diversity, internal/full-time orientation, financial research orientation and staff research orientation. Based on these six performance measures, universities were grouped into four to seven clusters and ranked on the basis of a single composite indicator. While arguably "a

\footnotetext{
2 The responsible Commonwealth department was known as the Department of Education, Training and Youth Affairs or DETYA until 1998.
} 
workable measure of the characteristics and performance of institutions in terms of their teaching and research activities” (DETYA, 1998, p.41) this study is dated and rather unwieldy.

As an alternative, Abbott and Doucouliagos (2003) examined the technical and scale efficiency of Australian universities with data envelopment analysis. After considering different measures of output and inputs (both teaching and research), it was concluded that the results were insensitive with respect to the selection of the chosen output-input mix, suggesting that Australian universities overall recorded high levels of relative efficiency. More recently, Abbott and Doucouliagos (2004) investigated the relationship between research output, research income, academic and non-academic labour and other university characteristics. They concluded that research income, academic staff and postgraduates were all positively related with research output, but that substantial differences exist, since a number of newer universities are finding it difficult to catch up with the more established universities in terms of research performance. Clearly such analyses add to our understanding of the production process in universities in Australia and elsewhere [see, for instance, Johnes and Johnes (1993; 1995), Johnes (1988; 1990; 1992; 1995), Beasley (1995), Glass et al. (1995a; 1995b), Coelli (1996), Athanassopoulos and Shale (1997), Carrico et al. (1997), Hashimoto and Cohn (1997), Glass et al. (1998), Ng and Li (2000)], but are computationally complex, rely on data difficult to obtain over time and are prone to misspecification and misinterpretation. Worthington (2001) provides a useful survey outlining the limitations of efficiency measurement techniques in educational contexts.

Finally, Williams and Van Dyke (2004) conducted a recent study on the international standing of Australian universities using a range of performance measures. These included the international standing of academic staff, the quality of the graduate and undergraduate programs, resource availability, and a subjective assessment of standing by surveyed educationists in Australia and overseas. In part, this study was intended to complement and confront some of the well-publicised (and often contentious) international rankings produced by the Institute of Higher Education at Shanghai Jiao Tong University (2003) and the Times Higher Education Supplement (2004) [for Australian media coverage see Aitkin (2004), Dodd (2004), Illing (2004a; 2004b) and Perry (2004; 2005)]. While encompassing a broad scale of measures, the resultant index indicated that the Group of Eight universities were highest ranked on an Australian basis, thereby confirming similar results from the international studies. However, given the reliance on surveyed perceptions of standing, the study by Williams and Van Dyke (2004) is unlikely to be easily replicated in the future. Other work on the ranking of university performance in Australia and overseas, either wholly or in part, include Bowden (2000), Clarke (2002), Federkeil (2002), 
Filinov and Ruchkina (2002), Vaughin (2002), Yonezawa et al. (2002) and Pomfret and Wang (2003).

The purpose of the present paper is to complement this nascent body of work with an analysis of the recent research performance of Australian universities. However, a clear point of departure is that the study is constructed so as to take advantage of the audited quantitative information on research performance periodically gathered by governmental authorities. This not only ensures that the results are objective, but may also be easily replicated in the future as additional data come to hand.

The paper itself is organised as follows. The next section provides a description of the data employed in the analysis. Then we discuss the clustering of university research performance followed by the ranking of research performance using factor analysis. The paper ends with some concluding remarks and policy recommendations in the final section.

\section{Data and Descriptive Analysis}

Thirty-six Australian universities have been included in the analysis, all of which are publicly funded and members of the Australian Vice-Chancellor's Committee (AVCC). Twenty-nine of these universities belong to one of four groupings: the Group of Seven (Go7); the Innovative Research Universities Australia (IRUA), the Australian Technology Network (ATN) and the New Generation Universities (NGU). A full list of these university groupings is included in Table 1. It should be noted that the Australian National University (ANU) has been excluded from this study because accurate and consistent research output data could not be obtained. However, the exclusion and inclusion of ANU did not change the ranking and clustering results of this study significantly. In fact the changes in the results were hardly noticeable. Thus we have decided to use the acronym “Go7” in lieu of Go8.

\section{$<$ TABLE 1 HERE $>$}

The performance measures specified in the analysis have all been obtained from DEST and comprise those measures included in its Composite Research Index. This index is calculated using an audited mix of the competitive funding and industry funding received, public sector research funding, research and scholarly publications and higher degree research completions. In order to minimise the bias in our results we consider only those academic staff members who are classified as undertaking 'research-only' and 'teaching-and-research' activities. In other words, the variable which is referred to as academic staff does not include 'teaching only' staff. The three measures of research output in our analysis are: (i) the average annual number of $\mathrm{PhD}$ completions; (ii) the average annual number of publications as weighted by DEST; and (iii) the 
total annual average amount of grants at 2002 prices measured by the sum of national competitive grants and industry grants, public and other funding. These three average research output measures have been calculated using data for the period 1998-2002. Notwithstanding the stated objective of this study to use publicly available research performance data, the exact specification of university research output remains a matter of some contention. For example, a distinction is usually made between quantity-based (bibliometric) measures [see, for instance, Abbot and Doucouliagos (2003)] and/or quality-based (peer review or citation) measures [see, for example, Athanassopoulos and Shale (1997) and Johnes and Johnes (1993)]. Similarly, while grants are technically an input, external research finance (especially industry linked grants) through reflection of the market value of research may serve as a proxy for output.

Table 2 presents a summary of descriptive statistics of the annual averages for the thirty-six universities during the period 1998-2002. Sample means, maxima, minima, standard deviations, skewness, kurtosis and Jacque-Bera statistics and p-values are reported. As shown, PhD completions average 99 per annum (Macquarie lies closest to the average) with a range between less than one (Sunshine Coast) and 366 (Melbourne); publications average 732 (La Trobe lies closest) with a range between 48 (Sunshine Coast) and 2585 (Melbourne); while grants average \$27.833 millions (Flinders is closest) and a range of \$0.335 million (Sunshine Coast) and \$127 million (Melbourne). The average number of academic staff is also included in Table 2, with Newcastle lying closest to the average of 818 and Sunshine Coast (84) and Queensland (2234) at the minimum and maximum, respectively. Finally, three univariate measures are calculated and included in Table 2: namely, PhD completions, publications and grants per academic staff (scaling in univariate ratio normally removes the size effects found across most organisations). On average, academics across all universities supervised about one-tenth of a $\mathrm{PhD}$ completion, contributed less than one publication and earned less than \$A 25,705 (at 2002 prices) in grants per academic staff member, per year during the period 1998-2002.

\section{$<$ TABLE 2 HERE $>$}

Given that the sampling distribution of skewness is normal with mean 0 and standard deviation of $\sqrt{6 / T}$ where $\mathrm{T}$ is the sample size, all of the series, with the exception of $\mathrm{PhD}$ completions and publications per academic staff, are significantly skewed. Since these are also positive, they signify the greater likelihood of observations lying above the mean than below. The kurtosis, or degree of excess, across all variables is also large, ranging from 1.88 ( $\mathrm{PhD}$ completions per academic staff) to 4.50 (total grants), thereby indicating leptokurtic distributions with many extreme observations. Given the sampling distribution of kurtosis is normal with mean 0 and standard deviation of $\sqrt{24 / T}$ where $\mathrm{T}$ is the sample size, then all estimates are once again 
statistically significant at any conventional level. Finally, the calculated Jarque-Bera statistics and corresponding p-values in Table 2 are used to test the null hypotheses that the variables are normally distributed. Apart from the per academic staff measures, all $p$-values are smaller than the .01 level of significance suggesting the null hypothesis can be rejected. Only the three per staff research output measures are then well approximated by the normal distribution.

\section{Clustering Research Performance}

The first methodological requirement is to cluster the research performance of Australian universities. Cluster analysis is a multivariate statistical technique that has been widely used to classify objects or items based on the similarity or dissimilarity of the characteristics they possess. This technique is especially relevant in the current context as it permits the minimisation of within-group variance and maximisation of between-group variance based on a range of research output indicators, resulting in heterogeneous groups with homogeneous contents (Hair, et al., 1998, p.470). This approach has been used to determine how many homogenous research groups exist and define exactly which comparable group each Australian university belongs to.

Before conducting the analysis, all six output variables were standardised so that they had a mean of 0 and a standard deviation of 1 . The following Euclidean distance is used as a dissimilarity measure to define the pairwise distance between universities:

$D(j, k)=\sum_{i=1}^{n=3}\left(X_{i j}-X_{i k}\right)^{2}$

where $\mathrm{X}_{\mathrm{ij}}$ and $\mathrm{X}_{\mathrm{ik}}$ represent the $\mathrm{i}^{\text {th }}$ measure of research output of universities $\mathrm{j}$ and $\mathrm{k}$, respectively. The smaller (larger) is $\mathrm{D}(\mathrm{j}, \mathrm{k})$, the more (less) similar are universities $\mathrm{j}$ and $\mathrm{k}$. In the present analysis, $\mathrm{n}=3$, representing the number of $\mathrm{PhD}$ completions, the number of publications and the amount of research grant in total and per academic staff. A brief technical explanation of hierarchical analysis has been provided in the Appendix.

A dendrogram (not shown) and agglomeration coefficients (Table 3) can then be used to determine the optimum number of clusters. Table 3 shows the agglomeration schedule at the various stages of hierarchical cluster analysis using both total and the normalized per academic staff research data. The agglomeration schedule in Table 3 is employed to determine the optimal number of clusters. In this approach, small variations in the agglomeration coefficient indicate that fairly homogeneous clusters are being merged. Likewise, if the agglomeration coefficient varies markedly between stages, it indicates that more heterogeneous cases are being clustered together. Given the percentage changes in the agglomeration coefficient at each step, it appears that the optimal number of clusters is 2 as the coefficient between stages 34 and 35 shows a 
significant increase from 36.94 to 105 (last and second-to-last rows in column 4 of Table 3). Exactly the same procedure is used to determine the number of clusters based on total research output measures. Clearly, with either specification the optimal number of clusters is 2 as in the case of total research performance the agglomeration coefficient again shows the biggest relative percentage change between stages 34 and 35 increasing from 17.88 to 105 (last and second-tolast rows in column 7 of Table 3). However, given that the use of the agglomeration coefficient as a stoping rule has a tendency to indicate too few clusters (Hair, 1998, p.503), the results of threecluster solutions for both total and per academic staff research performance are also included [the alternative cubic clustering criterion could have also been used as a stopping rule, but this has the tendency to indicate too many clusters].

\section{<TABLE 3 HERE>}

Table 4 presents the cluster membership for the 2-cluster (columns 2 and 4) and the 3cluster (columns 3 and 5) solutions for per academic staff research performance and total research output, respectively. It should be noted that nothing is implied from the ordering of universities in the first column outside of their cluster membership. In fact, to make the cluster membership codes even easier to analyse they are sorted according to the second, third and fourth columns. A cursory examination of Table 4 reveals that in any two-cluster solution, the Go7 members (Adelaide, Melbourne, Monash, New South Wales, Queensland, Sydney, and Western Australia) always belong to cluster A. This indicates that this group is relatively homogenous in terms of both factor and total productivity. But in a two-cluster solution based on per academic staff research performance, seven additional universities (Flinders, Macquarie, Murdoch, Newcastle, New England, Tasmania and Wollongong) are also included, taking cluster A membership to fourteen. This cluster of high-performing research universities then comprises the Go7, four Innovative Research Universities Australia (Flinders, Macquarie, Murdoch and Newcastle) and three Ungrouped Universities (New England, Tasmania and Wollongong). No Australian Technology Network or New Generation Universities are present.

\section{$<$ TABLE 4 HERE $>$}

With a three-cluster solution based on per academic staff research performance, the universities in cluster A, as in the two-cluster solution, remain unchanged but cluster B is now reclassified into clusters B1 and B2 with twelve and ten universities, respectively. The distances between final cluster centers can be used to compare clusters A, B1 and B2, and given that the pairwise distances between clusters $(\mathrm{A}-\mathrm{B} 1=2.31$; $\mathrm{A}-\mathrm{B} 2=3.72$ and $\mathrm{B} 1-\mathrm{B} 2=1.50$ ) we may conclude that in terms of staff productivity, the universities in clusters B1 and B2 are more similar than either are with cluster A. Put differently, there is little research performance 
difference between the bottom twenty-two universities in Table 4. This provides further ex post justification in the agglomeration coefficients in Table 3 justifying the formation of just two clusters.

Following MacQueen (1967), Milligan (1980) and Hair et al. (1998), we finetuned the results of the hierarchical cluster analysis (HCA) using a non-hierarchical procedure known as Kmeans clustering. The process involves four steps: (1) the centroids, $\left(\overline{\mathrm{X}}_{1 \mathrm{k}}, \overline{\mathrm{X}}_{2 \mathrm{k}}, \overline{\mathrm{X}}_{3 \mathrm{k}}\right)$, of the clusters formed by the hierarchical procedure are calculated and used as 'seeds' (Hair et al., 1998, p.497 and Green, 1978, p.428); (2) proceeding through the list of universities, each university is assigned to the cluster with the nearest centroid; (3) the centroids of the clusters receiving and losing the university are recalculated; and (4) Steps 2 and 3 are repeated until no more assignments can take place. The use of K-means cluster analysis technique has only slightly changed the cluster memberships produced by the HCA. Based on the "finetuned cluster centres" we have observed the distances between final cluster centres reported in the preceding paragraph.

As far as cluster membership based on total research performance is concerned, the results of a three-cluster solution are also similar to a two-cluster solution in that the universities in cluster B continue to be in the same cluster. However, cluster A is now sub-divided into clusters A1 and A2. In cluster A2, two members of the Go7 (Adelaide and Western Australia) separate from the others. But once again the agglomeration coefficient shows that the formation of three clusters is unnecessary. The results of an analysis of variance (ANOVA) across the three variables used in the clustering process also indicate that the cluster differences in terms of the standardised magnitudes of the means of the three performance measures are all highly significant, supporting the view that they all play an important role in differentiating the resulting clusters (the ANOVA results are not reported but they are available upon request from the corresponding author).

A number of salients points are noted from the cluster analysis of Australian university research performance. First, it is clear that the scale and long tenure of the Go7 universities places them in the highest (relative) grouping of research performance, whether in total or partial productivity terms. This is unsurprising. Second, what is more interesting is that once an attempt is made to take into account the vastly different scales of universities, and research performance is expressed in per academic staff terms, an additional seven universities (Flinders, Macquarie, Murdoch, New England, Newcastle, Tasmania and Wollongong) are virtually indistinguishable in terms of research performance. Third, none of the remaining twenty-two universities can be clustered with any of the Go7 even on a per academic staff basis. It would then appear that these other universities (particularly the ten classified in cluster B2 in column 3 of Table 4) are not only 
producing less research output, but also their productivity is at a much lower level. See also the results in the next section. Put otherwise, the least (most) research-productive universities are those with the least (most) total research output. Accordingly, if the proposed policy of classifying universities as 'research intensive', 'research and teaching' and 'teaching only' were to be implemented, and if this reflected recent historical research performance, guidelines to a logical grouping could be found in column 3 of Table 4.

\section{Ranking Research Performance}

The second methodological requirement is to rank Australian university research performance. In brief, the method involves using the first principal component to calculate a single normalised factor score for total and per academic staff research performance. These two composite indices are found to explain 99 and 87 percent of total variation of the three totals and per academic staff measures, respectively. Only the first eigenvalue in each case exceeds unity and according to the scree plot just the first principal component is sufficient. Also (i) Bartlett's test of sphericity is rejected at the 1 percent level for the respective total and per academic staff measures $[\chi(3)=$ 231.5, p-value $=0.000$ and $\chi(3)=78.1$, p-value $=0.000]$; (ii) the Kaiser-Meyer-Olkin measure of sampling adequacy for total and per academic staff performance are 0.787 and 0.760 , respectively; (iii) all of the elements on the diagonal of the anti-image correlation matrix are at least 0.730 ; and (iv) the lowest communality is 0.849 . The results of the factor analysis, as briefly outlined, suggest that they were statistically acceptable. These results are not reported here in details but they are available from the authors upon request.

Based on the results of the factor analysis, the regression method is used and the corresponding factor scores for each of the thirty-six universities are presented in Table 5 in descending order. In total research performance terms the results are once again fairly unsurprising with the Go7 universities ranking highest. However, when research performance is expressed in per academic staff terms Monash is longer among the top-seven Australian universities and is replaced instead by the University of Tasmania. Regardless of specification, the University of Melbourne is always ranked highest, followed by the Universities of Sydney, Queensland, New South Wales and Monash University in total research performance, and by the Universities of Adelaide, Western Australia, New South Wales and Sydney in per academic staff research performance. For those universities which improve in rank from total research performance to per academic staff research performance, it is clear that while total product is relatively lower, labour productivity is relatively higher. 
Given a less than perfectly correlated Spearman rank correlation coefficient of 0.858 significant at the 0.01 level (two-tailed) between the total and per academic staff research performance rank, one can well argue that in many universities they not only produce less output but also their staff productivity is relatively lower. But for a number of universities labour productivity is relatively less than total performance too. For example, according to columns 5 and 3 of Table 5, Monash changes from fifth to tenth-ranked in per academic staff terms, Queensland University of Technology from twelfth to twentieth-ranked and La Trobe from eighth to fifteenth-ranked. The reverse also exists with highly productive academic staff (changes in ranks between total and per academic staff research performance in brackets) at New England (twenty-second to eleventh-ranked), Tasmania (tenth to seventh-ranked), and Wollongong (sixteenth to eighth-ranked).

\section{$<$ TABLE 5 HERE $>$}

In addition, the twenty one universities appearing in the bottom of Table 5 (beginning with James Cook) have all negative factor scores (see columns 2 and 4), and therefore their research outputs are below average, in terms of both total research output and research output per staff member. These universities are consistently the worse performers in terms of both total and per academic staff research performance. All less productive universities shown in the bottom of Table 5 are among the twenty-two universities in Table 4 belonging to cluster B (either B1 or B2 depending upon the number of clusters) with the only exception being La Trobe. Moreover, all the top universities in terms of total or per academic staff research output in Table 5 were grouped in cluster A in Table 4. Therefore, both the cluster and factor analyses have generated consistent results in relation to the classification and the ranking of universities.

As a final point, the rankings provided in this analysis are broadly consistent with Williams and Van Dyke's (2004) Melbourne Institute Index of International Standing of Australian Universities with a Spearman rank correlation coefficient as high as 0.934 (significant at the 0.01 level). This is surprising when it is remembered that that particular index is a composite measure of overall international standing (percentage weights in brackets), encompassing the standing of staff (40), quality of graduate programs (16), quality of undergraduate entry (11), quality of undergraduate programs (14), resource levels (11) and opinions of educationists (8). Nevertheless, it is very likely that research performance, however defined, is correlated with any and all of these measures of international standing. Based on this result one may also conclude that the most productive institutions in terms of 'quantity' of research output also enjoy a higher international standing by offering ‘quality’ products. 


\section{Concluding Remarks}

This paper examined the clustering and ranking of Australian university research performance over the period 1998-2002. Hierarchical cluster analysis was used to cluster research performance, defined in terms of $\mathrm{PhD}$ completions, publications and grants, across Australia's thirty-six universities. The results indicate that two clusters are optimal, regardless of whether performance is expressed in total or per academic staff terms. In total research performance terms the Go7 universities comprise the better-performing cluster, but in per academic staff terms they are joined by seven other universities with high labour productivity. Clearly, when performance is expressed in total terms, the large, broad-disciplined, well-established Go7 universities outperform all others. But when appropriate recognition is made of the differing scale (and funding) of operations, the performance of the seven additional universities (Flinders, Macquarie, Murdoch, Newcastle, New England, Tasmania and Wollongong) is statistically indistinguishable. Interestingly, all of these universities were established in the pre-Dawkins era, and are not strict creations of the Dawkins reforms, whereby universities were joined by the onetime colleges of advanced education and institutes of technology. This reinforces the notion that research performance has a strong temporal component and that with time; the remaining twenty-two universities are likely to further improve.

Of course, this study does suffer from a number of limitations, all of which suggest further avenues of research. Certainly, the specification of inputs and outputs in education, especially tertiary education is difficult, as is modelling the production processes relating them. One avenue of research could examine how to expand the set of outputs used here to include, for example, measures of research quality. Another extension could incorporate the sizeable literature on frontier efficiency measurement techniques in education, especially non-parametric techniques. This could directly consider the variations in resources and scale that complicate and compromise most measures of international standing and ranking. Similarly, there is little allowance currently for changes in performance over time though 'learning by doing'. Future research should then attempt to lengthen time-series to enable such assessments to be made.

\section{REFERENCES}

Abbott, M and Doucouliagos, C. (2003) The efficiency of Australian universities: a data envelopment analysis, Economics of Education Review, 22(1) pp. 89-97.

Abbott, M. and Doucouliagos, H. (2004) Research output of Australian universities, Education Economics, 12(3), pp. 251-65.

Aitkin, D. (2004) Measuring the things we value most, Australian Financial Review, 29 November, p. 35

Athanassopoulos, A. and Shale, E. (1997) Assessing the comparative efficiency of higher education institutions in the UK by means of data envelopment analysis, Education Economics, 5(2), pp. 117-134.

Beasley, J.E. (1995) Determining teaching and research efficiencies, Journal of the Operational Research Society, 46, pp. 441-452. 
Bowden, R. (2000) Fantasy higher education: university and college league tables, Quality in Higher Education, 6(1), pp 41-60.

Carrico, C.S., Hogan, S.M., Dyson R.G. and Athanassopoulos, A.D. (1997) Data envelopment analysis and university selection”, The Journal of the Operational Research Society, 48(12), pp. 1163-1177.

Clarke, M. (2002) Some guidelines for academic quality rankings, Higher Education in Europe, XXVII(4), pp. 443459.

Coelli, T. (1996) Assessing the performance of Australian universities using data envelopment analysis, mimeo (Centre for Efficiency and Productivity Analysis, University of New England).

Department of Education, Training and Youth Affairs (1998) The characteristics and performance of higher education institutions, Occasional Paper Series 1A 98, Commonwealth of Australia, Canberra.

Dodd, T. (2004) Another high score for ANU, Australian Financial Review, 4 December, p. 16.

Federkeil, G. (2002) Some aspects of ranking methodology-the CHE-ranking of German universities, Higher Education in Europe, XXV11(4), pp. 389-

Filinov, N.B. and Ruchkina, S. (2002) The ranking of higher education institutions in Russia: some methodological problems, Higher Education in Europe, XXVII(4), pp. 407-421.

Glass, J. C, McKillop, D.G. and Hyndman, N. (1995a) Efficiency in the provision of university teaching and research: an empirical analysis of UK universities, Journal of Applied Econometrics,10(1), pp. 61-72.

Glass, J. C., McKillop, D.G. and Hyndman, N. (1995b) The achievement of scale efficiency in UK universities: a multiple-input multiple-output analysis, Education Economics, 3(3), pp. 249-263.

Glass, J. C., McKillop, D.G. and O’Rourke, G. (1998) A cost indirect evaluation of productivity change in UK universities, Journal of Productivity Analysis, 10(2), pp. 153-175.

Hair, J.F, Anderson, T.E., Tatham, R. L. and Black, W.C. (1998) Multivariate data analysis, $5^{\text {th }}$ edition, PrenticeHall, New Jersey.

Hashimoto, K. and Cohn, E. (1997) Economies of scale and scope in Japanese private universities, Education Economics, 5(2), pp. 107-115.

Illing, D. (2004a) Research elites win top spots, The Australian, 24 November, p. 23.

Illing, D. (2004b) Our unis worthy of global honour role, The Australian, 24 November, p. 2

Johnes, G. and Johnes, J. (1993) Measuring the research Performance of UK economics departments: an application of data envelopment analysis, Oxford Economic Papers, 45(2), pp. 332-341.

Johnes, G. \& Johnes, J. (1995) Research funding and performance in UK university departments of economics: a frontier analysis, Economics of Education Review, 14(3), pp. 301-314.

Johnes, G. (1988) Determinants of research output in economics departments in British universities, Research Policy, 17, pp. 171-178.

Johnes, G. (1990) Measures of research output: university departments of economics in the UK 1984-8, Economic Journal, 100, pp. 556-560.

Johnes, G. (1992) Performance indicators in higher education: a survey of recent work, Oxford Review of Economic Policy, 8, pp. 19-34.

Johnes, G. (1995) Scale and technical efficiency in the production of economic research: data envelopment analysis of the 1992 research assessment exercise of British university departments of economics, Applied Economics Letters, 2, pp. 7-11.

Milligan, G. (1980) An examination of the effect of six types of error perturbation on fifteen clustering algorithms, Psychometrika, 45, pp.325-42.

Ng, Y. C. \& Li, S. K. (2000) Measuring the research performance of Chinese higher education institutions: an application of data envelopment analysis, Education Economics, 8(2), pp. 140-156.

Perry, L. (2004) Ruction over global ranking, The Australian, 1 December, p. 37.

Perry, L. (2005) Fear of teaching-only stigma, The Australian, 27 April, p. 30

Pomfret, R. and Wang, L.C. (2003) Evaluating the research output of Australian universities, Australian Economic Papers, 42(4), pp. 418-41.

Shanghai Jiao Tong University (2003) Academic ranking of world universities, <http://www.sjtu.edu.cn/>, Accessed April 2004.

Times Higher Education Supplement (2004) World university rankings <http://www.thes.co.uk/>, Accessed April 2004.

Vaughin, J. (2002) Accreditation, commercial rankings, and new approaches to assessing the quality of university research and education programmes in the United States, Higher Education in Europe, 11(4), pp. 433-41. 
Williams, R. and Van Dyke, N. (2004) The international standing of Australian universities, Melbourne institute of applied economic and social research, University of Melbourne, Melbourne.

Worthington, A. C. (2001) An empirical survey of frontier efficiency measurement techniques in education, Education Economics, 9(3), pp. 245-265.

Yonezawa, A., Izuma, N. and Tetsuo K. (2002) University rankings in Japan, Higher Education in Europe, XXVII(4), pp. 373-382. 
TABLE 1. Average annual PhD completions, publications, academic staff and grants by university, 1998-2002

\begin{tabular}{|c|c|c|c|c|c|c|}
\hline No. & University & Group & $\begin{array}{l}\text { Academic staff } \\
\text { (persons) }\end{array}$ & $\begin{array}{c}\mathrm{PhD} \\
\text { completions } \\
\text { (persons) }\end{array}$ & $\begin{array}{l}\text { Publications } \\
\text { (DEST } \\
\text { weighted } \\
\text { points) } \\
\end{array}$ & $\begin{array}{c}\text { Grants } \\
\text { (\$m-2002 } \\
\text { prices) }\end{array}$ \\
\hline 1 & Adelaide & Go8 & 1,109 & 172 & 1236 & 64.30 \\
\hline 2 & Australian Catholic University & NGU & 344 & 8 & 125 & 1.66 \\
\hline 3 & Ballarat & NGU & 135 & 7 & 90 & 2.27 \\
\hline 4 & Canberra & UGU & 270 & 14 & 200 & 6.39 \\
\hline 5 & Central Queensland & NGU & 332 & 13 & 199 & 3.24 \\
\hline 6 & Charles Sturt & UGU & 451 & 19 & 225 & 4.01 \\
\hline 7 & Curtin University of Technology & ATN & 851 & 82 & 624 & 19.10 \\
\hline 8 & Deakin & UGU & 734 & 74 & 606 & 11.16 \\
\hline 9 & Edith Cowan & NGU & 538 & 25 & 484 & 4.54 \\
\hline 10 & Flinders & IRUA & 699 & 65 & 619 & 26.97 \\
\hline 11 & Griffith & IRUA & 939 & 85 & 733 & 21.59 \\
\hline 12 & James Cook & UGU & 502 & 69 & 333 & 10.29 \\
\hline 13 & La Trobe & UGU & 1,019 & 131 & 771 & 19.80 \\
\hline 14 & Macquarie & IRUA & 660 & 96 & 661 & 17.07 \\
\hline 15 & Melbourne & Go8 & 2,084 & 366 & 2585 & 126.95 \\
\hline 16 & Monash & Go8 & 2,078 & 275 & 2017 & 74.35 \\
\hline 17 & Murdoch & IRUA & 467 & 70 & 430 & 16.47 \\
\hline 18 & New England & UGU & 458 & 69 & 483 & 9.76 \\
\hline 19 & New South Wales & Go8 & 1,905 & 297 & 2060 & 102.08 \\
\hline 20 & Newcastle & IRUA & 833 & 72 & 767 & 26.85 \\
\hline 21 & Northern Territory & UGU & 155 & 14 & 91 & 3.45 \\
\hline 22 & Queensland & Go8 & 2,234 & 337 & 2349 & 111.71 \\
\hline 23 & Queensland University of Technology & ATN & 996 & 91 & 803 & 15.25 \\
\hline 24 & Royal Melbourne Institute of Technology & ATN & 989 & 91 & 529 & 16.88 \\
\hline 25 & South Australia & ATN & 797 & 65 & 565 & 17.66 \\
\hline 26 & Southern Cross & NGU & 254 & 33 & 136 & 4.28 \\
\hline 27 & Southern Queensland & NGU & 357 & 14 & 150 & 3.54 \\
\hline 28 & Sunshine Coast & NGU & 85 & 1 & 48 & 0.335 \\
\hline 29 & Swinburne University of Technology & UGU & 369 & 32 & 255 & 6.00 \\
\hline 30 & Sydney & Go8 & 2,226 & 364 & 2232 & 114.48 \\
\hline 31 & Tasmania & UGU & 631 & 93 & 614 & 25.31 \\
\hline 32 & University of Technology, Sydney & ATN & 728 & 62 & 498 & 11.90 \\
\hline 33 & Victoria University of Technology & NGU & 510 & 34 & 349 & 5.59 \\
\hline 34 & Western Australia & Go8 & 1,227 & 175 & 1370 & 68.22 \\
\hline 35 & Western Sydney & NGU & 901 & 54 & 513 & 10.32 \\
\hline 36 & Wollongong & UGU & 583 & 86 & 597 & 18.23 \\
\hline
\end{tabular}

Notes: PhD completions and academic staff are in persons, publications are in DEST-weighted points, grants (total average sum of national competitive grants and industry grants, public and other funding) are at the constant 2002 prices based on the author's calculations. Go8=Group of Eight; IRUA=Innovative Research Universities Australia; ATN=Australian Technology Network; NGU=New Generation Universities; and UGU= Ungrouped Universities.

Sources: Department of Education, Science and Training (DEST), Higher Education Report for the 2002 to 2004 Triennium. (www.dest.gov.au); Higher Education Statistics Collection-various years (www.detya.gov.au); Australian Vice-Chancellor's Committee (AVCC) (www.avcc.gov.au); Australian Bureau of Statistics (2005), Consumer Price Index, Cat. No. 6401, Canberra. 
TABLE 2. Descriptive statistics of the data employed, 1998-2002

\begin{tabular}{|c|c|c|c|c|c|c|c|c|}
\hline Variables & Mean & Maximum & Minimum & Std. dev. & Skewness & Kurtosis & Jarque-Bera & P-value \\
\hline Academic Staff (persons) & 818 & 2234 & 84 & 597 & 1.231 & 3.615 & 9.666 & 0.008 \\
\hline PhD completions (persons) & 99 & 366 & 1 & 103 & 1.548 & 4.286 & 16.857 & 0.000 \\
\hline Publications (DEST points) & 732 & 2585 & 48 & 688 & 1.476 & 4.077 & 14.819 & 0.001 \\
\hline Grants (2002 \$million ) & 27.833 & 127.000 & 0.335 & 35.602 & 1.691 & 4.510 & 20.585 & 0.000 \\
\hline $\begin{array}{l}\text { PhD completions per } \\
\text { academic staff (persons) }\end{array}$ & 0.101 & 0.176 & 0.010 & 0.046 & -0.191 & 1.884 & 2.088 & 0.352 \\
\hline $\begin{array}{l}\text { Publications per academic } \\
\text { staff (DEST point) }\end{array}$ & 0.797 & 1.240 & 0.365 & 0.220 & 0.022 & 2.089 & 1.247 & 0.536 \\
\hline $\begin{array}{l}\text { Grants per academic staff } \\
(2002 \$)\end{array}$ & 25705 & 60910 & 4006 & 16048 & 0.802 & 2.549 & 4.166 & 0.125 \\
\hline
\end{tabular}

Sources: Based on Table 1 and the authors' calculations.

TABLE 3. Agglomeration schedule based on the Ward linkage

\begin{tabular}{|c|c|c|c|c|c|c|}
\hline \multirow{3}{*}{ Stage } & \multicolumn{3}{|c|}{$\begin{array}{c}\text { Research performance per academic } \\
\text { staff }\end{array}$} & \multicolumn{3}{|c|}{ Total research performance } \\
\hline & \multicolumn{2}{|c|}{ Combined cluster } & \multirow[t]{2}{*}{ Coefficients } & \multicolumn{2}{|c|}{ Combined cluster } & \multirow[t]{2}{*}{ Coefficients } \\
\hline & Cluster 1 & Cluster 2 & & Cluster 1 & Cluster 2 & \\
\hline (1) & (2) & (3) & (4) & (5) & (6) & (7) \\
\hline 1 & 29 & 32 & 0.001 & 2 & 3 & 0.002 \\
\hline 2 & 8 & 23 & 0.024 & 7 & 36 & 0.004 \\
\hline 3 & 7 & 11 & 0.054 & 5 & 6 & 0.006 \\
\hline 4 & 19 & 22 & 0.094 & 21 & 27 & 0.010 \\
\hline 5 & 1 & 34 & 0.140 & 32 & 35 & 0.014 \\
\hline 6 & 14 & 36 & 0.205 & 4 & 5 & 0.018 \\
\hline 7 & 6 & 27 & 0.270 & 2 & 21 & 0.025 \\
\hline 8 & 17 & 31 & 0.345 & 18 & 32 & 0.035 \\
\hline 9 & 7 & 25 & 0.423 & 29 & 33 & 0.044 \\
\hline 10 & 21 & 24 & 0.502 & 7 & 14 & 0.058 \\
\hline 11 & 19 & 30 & 0.593 & 7 & 24 & 0.075 \\
\hline 12 & 16 & 17 & 0.692 & 2 & 28 & 0.094 \\
\hline 13 & 10 & 20 & 0.796 & 11 & 20 & 0.114 \\
\hline 14 & 5 & 35 & 0.903 & 17 & 25 & 0.136 \\
\hline 15 & 12 & 13 & 1.020 & 1 & 34 & 0.161 \\
\hline 16 & 3 & 33 & 1.170 & 8 & 18 & 0.190 \\
\hline 17 & 14 & 18 & 1.335 & 4 & 26 & 0.220 \\
\hline 18 & 3 & 5 & 1.578 & 10 & 31 & 0.256 \\
\hline 19 & 7 & 29 & 1.839 & 10 & 11 & 0.297 \\
\hline 20 & 1 & 19 & 2.118 & 8 & 17 & 0.341 \\
\hline 21 & 2 & 6 & 2.412 & 9 & 29 & 0.393 \\
\hline 22 & 7 & 8 & 2.855 & 22 & 30 & 0.445 \\
\hline 23 & 12 & 26 & 3.300 & 8 & 12 & 0.512 \\
\hline 24 & 2 & 28 & 3.899 & 2 & 4 & 0.584 \\
\hline 25 & 3 & 4 & 4.521 & 7 & 23 & 0.656 \\
\hline 26 & 1 & 15 & 5.364 & 7 & 10 & 0.795 \\
\hline 27 & 14 & 16 & 6.234 & 7 & 13 & 1.000 \\
\hline 28 & 7 & 21 & 7.366 & 15 & 22 & 1.237 \\
\hline 29 & 3 & 9 & 8.566 & 2 & 9 & 1.539 \\
\hline 30 & 7 & 12 & 10.582 & 16 & 19 & 1.866 \\
\hline 31 & 10 & 14 & 13.144 & 7 & 8 & 2.582 \\
\hline 32 & 2 & 3 & 16.820 & 15 & 16 & 4.263 \\
\hline 33 & 1 & 10 & 25.798 & 2 & 7 & 10.207 \\
\hline 34 & 2 & 7 & 36.941 & 1 & 15 & 17.882 \\
\hline 35 & 1 & 2 & 105.000 & 1 & 2 & 105.000 \\
\hline
\end{tabular}

Source: The Authors' calculations using the normalised data. 
TABLE 4. Cluster membership based on per staff and total research output measures

\begin{tabular}{|c|c|c|c|c|}
\hline \multirow{2}{*}{$\begin{array}{l}\text { University } \\
\\
\text { (1) }\end{array}$} & \multicolumn{2}{|c|}{$\begin{array}{c}\text { Research } \\
\text { performance per } \\
\text { academic staff }\end{array}$} & \multicolumn{2}{|c|}{$\begin{array}{l}\text { Total research } \\
\text { performance }\end{array}$} \\
\hline & $\begin{array}{l}2 \text { Clusters } \\
(2)\end{array}$ & $\begin{array}{l}3 \text { Clusters } \\
\text { (3) }\end{array}$ & $\begin{array}{l}2 \text { Clusters } \\
(4)\end{array}$ & $\begin{array}{c}3 \text { Clusters } \\
(5)\end{array}$ \\
\hline Adelaide & $\mathrm{A}$ & $\mathrm{A}$ & $\mathrm{A}$ & A2 \\
\hline Melbourne & A & A & A & A1 \\
\hline Monash & A & A & A & A1 \\
\hline New South Wales & A & A & A & A1 \\
\hline Queensland & A & A & A & A1 \\
\hline Sydney & A & A & A & A1 \\
\hline Western Australia & A & A & A & A2 \\
\hline Flinders & A & A & B & B \\
\hline Macquarie & A & A & B & B \\
\hline Murdoch & A & A & B & B \\
\hline New England & A & A & B & B \\
\hline Newcastle & A & A & B & B \\
\hline Tasmania & A & A & B & B \\
\hline Wollongong & A & A & B & B \\
\hline Australian Catholic University & B & B2 & B & B \\
\hline Ballarat & B & B2 & B & B \\
\hline Canberra & B & B2 & B & B \\
\hline Central Queensland & B & B2 & B & B \\
\hline Charles Sturt & B & B2 & B & B \\
\hline Edith Cowan & B & B2 & B & B \\
\hline Southern Queensland & B & B2 & B & B \\
\hline Sunshine Coast & B & B2 & B & B \\
\hline Victoria University of Technology & B & B2 & B & B \\
\hline Western Sydney & B & B2 & B & B \\
\hline Curtin University of Technology & B & B1 & B & B \\
\hline Deakin & B & B1 & B & B \\
\hline Griffith & B & B1 & B & B \\
\hline James Cook & B & B1 & B & B \\
\hline La Trobe & B & B1 & B & B \\
\hline Northern Territory & B & B1 & B & B \\
\hline Queensland University of Technology & B & B1 & B & B \\
\hline Royal Melbourne Institute of Technology & B & B1 & B & B \\
\hline South Australia & B & B1 & B & B \\
\hline Southern Cross & B & B1 & B & B \\
\hline Swinburne University of Technology & B & B1 & B & B \\
\hline University of Technology, Sydney & B & B1 & B & B \\
\hline
\end{tabular}

Source: The authors' calculations using the normalised data. 
TABLE 5. Ranking of universities based on factor scores

\begin{tabular}{|c|c|c|c|c|c|c|}
\hline \multirow[b]{2}{*}{ Institution } & \multicolumn{4}{|c|}{ Normalised factor scores } & \multirow{3}{*}{$\begin{array}{l}\text { Melbourne } \\
\text { Institute } \\
\text { Index } \\
\\
\text { (6) }\end{array}$} & \multirow{3}{*}{$\begin{array}{r}\text { Rank } \\
\quad(7)\end{array}$} \\
\hline & \multicolumn{2}{|c|}{$\begin{array}{l}\text { Research performance } \\
\text { per academic staff }\end{array}$} & \multicolumn{2}{|c|}{$\begin{array}{l}\text { Total research } \\
\text { performance }\end{array}$} & & \\
\hline (1) & $\begin{array}{r}\text { Score } \\
(2)\end{array}$ & $\begin{array}{r}\text { Rank } \\
\text { (3) }\end{array}$ & $\begin{array}{r}\text { Score } \\
(4)\end{array}$ & $\begin{array}{r}\text { Rank } \\
\text { (5) }\end{array}$ & & \\
\hline Melbourne & 2.091 & 1 & 2.707 & 1 & 100 & 1 \\
\hline Adelaide & 1.660 & 2 & 0.827 & 7 & 70 & 8 \\
\hline Western Australia & 1.517 & 3 & 0.941 & 6 & 76 & 6 \\
\hline New South Wales & 1.516 & 4 & 1.993 & 4 & 85 & 5 \\
\hline Sydney & 1.398 & 5 & 2.412 & 2 & 95 & 3 \\
\hline Queensland & 1.347 & 6 & 2.355 & 3 & 87 & 4 \\
\hline Tasmania & 0.968 & 7 & -0.101 & 10 & 53 & 12 \\
\hline Wollongong & 0.862 & 8 & -0.196 & 16 & 50 & 15 \\
\hline Murdoch & 0.798 & 9 & -0.348 & 20 & 51 & 14 \\
\hline Monash & 0.754 & 10 & 1.640 & 5 & 76 & 6 \\
\hline New England & 0.703 & 11 & -0.389 & 22 & 47 & 19 \\
\hline Macquarie & 0.681 & 12 & -0.144 & 13 & 54 & 11 \\
\hline Flinders & 0.379 & 13 & -0.172 & 14 & 56 & 9 \\
\hline Newcastle & 0.234 & 14 & -0.080 & 9 & 52 & 13 \\
\hline La Trobe & 0.007 & 15 & 0.048 & 8 & 55 & 10 \\
\hline James Cook & -0.048 & 16 & -0.455 & 24 & 46 & 22 \\
\hline Griffith & -0.166 & 17 & -0.102 & 11 & 49 & 16 \\
\hline Deakin & -0.196 & 18 & -0.300 & 19 & 47 & 19 \\
\hline Curtin University of Technology & -0.216 & 19 & -0.190 & 15 & 49 & 16 \\
\hline Queensland University of Technology & -0.293 & 20 & -0.109 & 12 & 49 & 16 \\
\hline South Australia & -0.374 & 21 & -0.288 & 18 & 44 & 24 \\
\hline Southern Cross & -0.401 & 22 & -0.726 & 28 & 39 & 30 \\
\hline Northern Territory & -0.496 & 23 & -0.818 & 33 & 41 & 27 \\
\hline Swinburne University of Technology & -0.498 & 24 & -0.656 & 27 & 46 & 22 \\
\hline Canberra & -0.519 & 25 & -0.738 & 30 & 42 & 26 \\
\hline University of Technology, Sydney & -0.521 & 26 & -0.385 & 21 & 47 & 19 \\
\hline Edith Cowan & -0.644 & 27 & -0.581 & 25 & 41 & 27 \\
\hline Royal Melbourne Institute of Technology & -0.690 & 28 & -0.227 & 17 & 43 & 25 \\
\hline Victoria University of Technology & -0.777 & 29 & -0.606 & 26 & 41 & 27 \\
\hline Ballarat & -0.816 & 30 & -0.854 & 35 & 38 & 33 \\
\hline Western Sydney & -1.008 & 31 & -0.417 & 23 & 39 & 30 \\
\hline Central Queensland & -1.151 & 32 & -0.770 & 31 & 37 & 34 \\
\hline Charles Sturt & -1.320 & 33 & -0.731 & 29 & 39 & 30 \\
\hline Southern Queensland & -1.438 & 34 & -0.787 & 32 & 36 & 36 \\
\hline Sunshine Coast & -1.560 & 35 & -0.912 & 36 & 32 & 37 \\
\hline Australian Catholic University & -1.783 & 36 & -0.839 & 34 & 37 & 34 \\
\hline
\end{tabular}




\section{Appendix}

A hierarchical clustering technique has been employed to define clusters of similar universities. At the beginning of the hierarchical procedure we had thirty-six clusters each containing only one university. Then, at each stage that followed, the two most similar clusters were combined until, at the final stage, a single cluster of thirty-six universities was created. The results of hierarchical analysis can be different depending on the way in which the most similar pair of clusters is defined at each stage. The Ward's (1963) method has been used in this paper, which identifies the two clusters whose merger would result in the minimum increase to the aggregate sum of squared deviations within clusters. The sum of squared deviations within Cluster $\mathrm{k}$ is calculated as follows:

$\operatorname{ESS}(\mathrm{k})=\sum_{\mathrm{j} \in \mathrm{k}} \sum_{\mathrm{i}=1}^{3}\left(\mathrm{X}_{\mathrm{ijk}}-\overline{\mathrm{X}}_{\mathrm{ik}}\right)^{2}$

where $\mathrm{X}_{\mathrm{ijk}}$ is the $\mathrm{i}^{\text {th }}$ measure of research output by university $\mathrm{j}$ in Cluster $\mathrm{k}$, and $\overline{\mathrm{X}}_{\mathrm{ik}}$ is the $\mathrm{i}^{\text {th }}$ measure of research output averaged across all universities in Cluster $\mathrm{k}$. With the sum of squared deviations within (say) Cluster K given by ESS(K), the increment to the total sum of squared deviations within clusters resulting from the combination of Cluster $\mathrm{k}$ and Cluster $\mathrm{K}$ to make Cluster $(\mathrm{k} \cup \mathrm{K})$ can be computed by:

$\mathrm{d}_{\mathrm{Ward}}(\mathrm{k}, \mathrm{K})=\sum_{\mathrm{j} \in(\mathrm{k} \cup \mathrm{K})} \sum_{\mathrm{i}=1}^{3}\left(\mathrm{X}_{\mathrm{ij}(\mathrm{k} \cup \mathrm{K})}-\overline{\mathrm{X}}_{\mathrm{i}(\mathrm{k} \cup \mathrm{K})}\right)^{2}-\mathrm{ESS}(\mathrm{k})-\mathrm{ESS}(\mathrm{K})$

Table A.1 shows the proximity matrix among the thirty-six universities using the normalised data on per staff research measures and the Squared Euclidean Distance (SED) as a measure of dissimilarity where higher (lower) SEDs are associated with more (less) dissimilar universities. This matrix is then quite useful for universities to identify their single most similar (and dissimilar) pairing in terms of research performance. On the basis of the three selected performance criteria ( $\mathrm{PhD}$ completions, publications and grants all expressed in per staff), this matrix provides a comprehensive snapshot of the pairwise differences among Australian universities. For example, the five most dissimilar pairs (SED in brackets) in descending order are: Melbourne-Australian Catholic University (39.434); Sunshine Coast-Melbourne (35.085); Australian Catholic University-Adelaide (31.094); Charles Sturt-Melbourne (30.504); and Central Queensland-Melbourne (27.512). On the other hand, the five most similar pairs are: UTSSwinburne (0.002); Queensland University of Technology-Deakin (0.046); Curtin-Griffith (0.060); New South Wales-Queensland (0.081); and Western Australia-Adelaide (0.091). These similarities and differences are not counterintuitive to the impartial observer. 
TABLE A1. Proximity matrix using per staff research measures and the squared Euclidean distance as a measure of dissimilarity

\begin{tabular}{|c|c|c|c|c|c|c|c|c|c|c|c|c|c|c|c|c|c|c|c|c|}
\hline No. & University & 1 & 2 & 3 & 4 & 5 & 6 & 7 & 8 & 9 & 10 & 11 & 12 & 13 & 14 & 15 & 16 & 17 & 18 & 19 \\
\hline 1 & Adelaide & 0.000 & 31.094 & 16.151 & 12.607 & 20.864 & 23.349 & 9.588 & 10.279 & 16.165 & 4.340 & 9.041 & 9.818 & 8.750 & 4.315 & 0.568 & 2.581 & 2.780 & 5.303 & 0.097 \\
\hline 2 & Australian Catholic & 31.094 & 0.000 & 2.777 & 4.746 & 1.382 & 0.624 & 6.636 & 7.736 & 6.255 & 12.530 & 7.128 & 9.268 & 9.452 & 17.432 & 39.434 & 17.192 & 17.895 & 18.816 & 28.497 \\
\hline 3 & Ballarat & 16.151 & 2.777 & 0.000 & 0.309 & 0.323 & 0.848 & 1.276 & 1.801 & 1.415 & 3.814 & 1.262 & 3.877 & 3.236 & 7.143 & 22.115 & 6.687 & 7.597 & 8.154 & 14.344 \\
\hline 4 & Canberra & 12.607 & 4.746 & 0.309 & 0.000 & 1.241 & 2.130 & 0.968 & 1.575 & 1.421 & 2.161 & 0.785 & 3.811 & 2.943 & 5.691 & 17.967 & 4.831 & 5.888 & 6.758 & 11.136 \\
\hline 5 & Central Queensland & 20.864 & 1.382 & 0.323 & 1.241 & 0.000 & 0.213 & 2.487 & .905 & 1.906 & 6.320 & 2.592 & 5.137 & 4.619 & 9.699 & 27.512 & 9.596 & 10.487 & 10.650 & 18.734 \\
\hline 6 & Charles Sturt & 23.349 & 0.624 & 0.848 & 2.130 & 0.213 & 0.000 & 3.251 & 3.993 & 3.353 & 7.833 & 3.565 & 5.522 & 5.405 & 11.509 & 30.504 & 11.372 & 12.026 & 12.649 & 21.051 \\
\hline 7 & Curtin University of & 9.588 & 6.636 & 1.276 & 0.968 & 2.487 & 3.251 & 0.000 & 0.385 & 2.520 & 1.503 & 0.060 & 0.979 & 0.556 & 2.716 & 14.133 & 2.505 & 2.786 & 3.568 & 8.017 \\
\hline 8 & Deakin & 10.279 & 7.736 & 1.801 & 1.575 & 2.905 & 3.993 & 0.385 & 0.000 & 1.700 & 2.226 & 0.320 & 1.343 & 0.546 & 2.074 & 14.427 & 2.588 & 2.955 & 2.444 & 8.583 \\
\hline 9 & Edith Cowan & 16.165 & 6.255 & 1.415 & 1.421 & 1.906 & 3.353 & 2.520 & 1.700 & 0.000 & 4.617 & 2.072 & 5.796 & 4.143 & 6.152 & 21.157 & 6.596 & 8.000 & 6.347 & 14.396 \\
\hline 10 & Flinders & 4.340 & 12.530 & 3.814 & 2.161 & 6.320 & 7.833 & 1.503 & 2.226 & 4.617 & 0.000 & 1.183 & 3.266 & 2.356 & 2.204 & 7.762 & 0.907 & 1.599 & 3.290 & 3.530 \\
\hline 11 & Griffith & 9.041 & 7.128 & 1.262 & 0.785 & 2.592 & 3.565 & 0.060 & 0.320 & 2.072 & 1.183 & 0.000 & 1.392 & 0.742 & 2.486 & 13.430 & 2.224 & 2.690 & 3.273 & 7.558 \\
\hline 12 & James Cook & 9.818 & 9.268 & 3.877 & 3.811 & 5.137 & 5.522 & 0.979 & 1.343 & 5.796 & 3.266 & 1.392 & 0.000 & 0.235 & 2.501 & 13.932 & 2.887 & 2.305 & 3.262 & 8.043 \\
\hline 13 & La Trobe & 8.750 & 9.452 & 3.236 & 2.943 & 4.619 & 5.405 & 0.556 & 0.546 & 4.143 & 2.356 & 0.742 & 0.235 & 0.000 & 1.530 & 12.591 & 1.990 & 1.761 & 2.082 & 7.077 \\
\hline 14 & Macquarie & 4.315 & 17.432 & 7.143 & 5.691 & 9.699 & 11.509 & 2.716 & 2.074 & 6.152 & 2.204 & 2.486 & 2.501 & 1.530 & 0.000 & 6.396 & 0.484 & 0.485 & 0.152 & 3.174 \\
\hline 15 & Melbourne & 0.568 & 39.434 & 22.115 & 17.967 & 27.512 & 30.504 & 14.133 & 14.427 & 21.157 & 7.762 & 13.430 & 13.932 & 12.591 & 6.396 & 0.000 & 4.852 & 4.971 & 7.115 & 0.916 \\
\hline 16 & Monash & 2.581 & 17.192 & 6.687 & 4.831 & 9.596 & 11.372 & 2.505 & 2.588 & 6.596 & 0.907 & 2.224 & 2.887 & 1.990 & 0.484 & 4.852 & 0.000 & 0.198 & 1.111 & 1.750 \\
\hline 17 & Murdoch & 2.780 & 17.895 & 7.597 & 5.888 & 10.487 & 12.026 & 2.786 & 2.955 & 8.000 & 1.599 & 2.690 & 2.305 & 1.761 & 0.485 & 4.971 & 0.198 & 0.000 & 1.132 & 1.849 \\
\hline 18 & New England & 5.303 & 18.816 & 8.154 & 6.758 & 10.650 & 12.649 & 3.568 & 2.444 & 6.347 & 3.290 & 3.273 & 3.262 & 2.082 & 0.152 & 7.115 & 1.111 & 1.132 & 0.000 & 4.078 \\
\hline 19 & & 0.097 & 28.497 & 14.344 & 11.136 & 18.734 & 21.051 & 8.017 & 8.583 & 14.396 & 3.530 & 7.558 & 8.043 & 7.077 & 3.174 & 0.916 & 1.750 & 1.849 & 4.078 & 0.000 \\
\hline 20 & Newcastle & 5.623 & 11.291 & 2.938 & 1.529 & 5.126 & 6.751 & 1.142 & 1.410 & 2.975 & 0.208 & 0.747 & 3.210 & 2.045 & 1.992 & 9.162 & 1.135 & 1.997 & 2.807 & 4.650 \\
\hline 21 & Northern Territory & 12.687 & 4.499 & 1.109 & 1.296 & 1.861 & 2.020 & 0.460 & 1.410 & 3.759 & 2.915 & 0.786 & 1.186 & 1.296 & 5.027 & 18.094 & 4.593 & 4.647 & 6.226 & 10.913 \\
\hline 22 & Queensland & 0.336 & 25.675 & 12.361 & 9.451 & 16.428 & 18.606 & 6.505 & 7.003 & 12.458 & 2.646 & 6.095 & 6.594 & 5.669 & 2.332 & 1.494 & 1.083 & 1.192 & 3.199 & 0.081 \\
\hline 23 & Queensland U & 10.980 & 6.768 & 1.281 & 1.126 & 2.266 & 3.295 & 0.318 & 0.046 & 1.338 & 2.241 & 0.243 & 1.593 & 0.782 & 2.637 & 15.399 & 3.006 & 3.489 & 3.091 & 9.272 \\
\hline 24 & Royal Melbourne Inst & 15.356 & .541 & 1.251 & 1.876 & 1.584 & 1.493 & 0.937 & 1.786 & 4.065 & 4.368 & 1.389 & 1.401 & 1.677 & 6.169 & 21.132 & 6.081 & 5.998 & 7.298 & 13.335 \\
\hline 25 & South Australia & 10.982 & 5.314 & 0.655 & 0.471 & 1.663 & 2.350 & 0.114 & 0.636 & 2.078 & 1.773 & 0.150 & 1.607 & 1.141 & 3.800 & 15.949 & 3.396 & 3.871 & 4.761 & 9.384 \\
\hline 26 & Southern Cross & 13.793 & 6.751 & 3.487 & 4.038 & 4.126 & 3.976 & 1.480 & 2.152 & 6.372 & 5.008 & 2.114 & 0.415 & 1.035 & 4.894 & 18.813 & 5.300 & 4.587 & 5.849 & 11.729 \\
\hline 27 & Southern Queensland & 25.274 & 0.323 & 1.467 & 2.950 & 0.657 & 0.131 & 4.127 & 5.226 & 4.788 & 9.071 & 4.578 & 6.257 & 6.436 & 13.303 & 32.846 & 12.969 & 13.498 & 14.663 & 22.907 \\
\hline 28 & Sunshine Coast & 27.556 & 0.970 & 1.564 & 2.936 & 0.597 & 0.717 & 5.438 & 5.760 & 2.940 & 10.091 & 5.468 & 9.176 & 8.424 & 14.562 & 35.085 & 14.482 & 15.817 & 15.501 & 25.227 \\
\hline 29 & Swinburne University & 12.731 & 4.694 & 0.682 & 0.857 & 1.357 & 1.922 & 0.229 & 0.467 & 1.907 & 2.752 & 0.350 & 1.384 & 0.985 & 4.037 & 17.829 & 4.127 & 4.462 & 4.809 & 10.903 \\
\hline 30 & Sydney & 0.463 & 26.492 & 13.328 & 10.473 & 17.443 & 19.404 & 6.973 & 7.683 & 14.029 & 3.275 & 6.715 & 6.421 & 5.819 & 2.694 & 1.590 & 1.436 & 1.235 & 3.668 & 0.176 \\
\hline 31 & Tasmania & 1.683 & 20.013 & 8.698 & 6.574 & 11.972 & 13.763 & 3.665 & 3.921 & 8.904 & 1.540 & 3.432 & 3.528 & 2.794 & 0.805 & 3.552 & 0.174 & 0.149 & 1.517 & 0.988 \\
\hline 32 & University of Techno & 12.949 & 4.502 & 0.618 & 0.818 & 1.263 & 1.800 & 0.256 & 0.533 & 1.915 & 2.814 & 0.383 & 1.457 & 1.072 & 4.222 & 18.116 & 4.277 & 4.624 & 5.020 & 11.115 \\
\hline 33 & Victoria University & 16.132 & 3.232 & 0.299 & 0.820 & 0.503 & 1.036 & 0.962 & 1.009 & 1.193 & 4.156 & 1.025 & 2.797 & 2.201 & 5.908 & 21.771 & 6.157 & 6.780 & 6.590 & 14.133 \\
\hline 34 & Western Australia & 0.091 & 28.727 & 14.293 & 10.896 & 18.781 & 21.278 & 8.369 & & 14.104 & 3.383 & 7.770 & 9.055 & 7.848 & 3.713 & 0.943 & 2.014 & 2.409 & 4.665 & 0.122 \\
\hline 35 & Western Sydney & 18.894 & 1.726 & 0.360 & 1.239 & 0.213 & 0.284 & 1.646 & 2.186 & 2.386 & 5.490 & 1.896 & 3.439 & 3.232 & 8.190 & 25.261 & 8.169 & 8.678 & 9.182 & 16.763 \\
\hline 36 & Wollongong & 2.955 & 19.390 & 8.226 & 6.402 & 11.168 & 13.112 & 3.380 & 2.940 & 7.358 & 2.039 & 3.091 & 3.215 & 2.217 & 0.129 & 4.735 & 0.258 & 0.286 & 0.407 & 2.029 \\
\hline
\end{tabular}




\begin{tabular}{|c|c|c|c|c|c|c|c|c|c|c|c|c|c|c|c|c|c|c|}
\hline No. & University & 20 & 21 & 22 & 23 & 24 & 25 & 26 & 27 & 28 & 29 & 30 & 31 & 32 & 33 & 34 & 35 & 36 \\
\hline 1 & Adelaide & 5.623 & 12.687 & 0.336 & 10.980 & 15.356 & 10.982 & 13.793 & 25.274 & 27.556 & 12.731 & 0.463 & 1.683 & 12.949 & 16.132 & 0.091 & 18.894 & 2.955 \\
\hline 2 & Australian Catholic & 11.291 & 4.499 & 25.675 & 6.768 & 3.541 & 5.314 & 6.751 & 0.323 & 0.970 & 4.694 & 26.492 & 20.013 & 4.502 & 3.232 & 28.727 & 1.726 & 19.390 \\
\hline 3 & Ballarat & 2.938 & 1.109 & 12.361 & 1.281 & 1.251 & 0.655 & 3.487 & 1.467 & 1.564 & 0.682 & 13.328 & 8.698 & 0.618 & 0.299 & 14.293 & 0.360 & 8.226 \\
\hline 4 & Canberra & 1.529 & 1.296 & 9.451 & 1.126 & 1.876 & 0.471 & 4.038 & 2.950 & 2.936 & 0.857 & 10.473 & 6.574 & 0.818 & 0.820 & 10.896 & 1.239 & 6.402 \\
\hline 5 & Central Queensland & 5.126 & 1.861 & 16.428 & 2.266 & 1.584 & 1.663 & 4.126 & 0.657 & 0.597 & 1.357 & 17.443 & 11.972 & 1.263 & 0.503 & 18.781 & 0.213 & 11.168 \\
\hline 6 & Charles Sturt & 6.751 & 2.020 & 18.606 & 3.295 & 1.493 & 2.350 & 3.976 & 0.131 & 0.717 & 1.922 & 19.404 & 13.763 & 1.800 & 1.036 & 21.278 & 0.284 & 13.112 \\
\hline 7 & Curtin University of & 1.142 & 0.460 & 6.505 & 0.318 & 0.937 & 0.114 & 1.480 & 4.127 & 5.438 & 0.229 & 6.973 & 3.665 & 0.256 & 0.962 & 8.369 & 1.646 & 3.380 \\
\hline 8 & Deakin & 1.410 & 1.410 & 7.003 & 0.046 & 1.786 & 0.636 & 2.152 & 5.226 & 5.760 & 0.467 & 7.683 & 3.921 & 0.533 & 1.009 & 8.970 & 2.186 & 2.940 \\
\hline 9 & Edith Cowan & 2.975 & 3.759 & 12.458 & 1.338 & 4.065 & 2.078 & 6.372 & 4.788 & 2.940 & 1.907 & 14.029 & 8.904 & 1.915 & 1.193 & 14.104 & 2.386 & 7.358 \\
\hline 10 & Flinders & 0.208 & 2.915 & 2.646 & 2.241 & 4.368 & 1.773 & 5.008 & 9.071 & 10.091 & 2.752 & 3.275 & 1.540 & 2.814 & 4.156 & 3.383 & 5.490 & 2.039 \\
\hline 11 & Griffith & 0.747 & 0.786 & 6.095 & 0.243 & 1.389 & 0.150 & 2.114 & 4.578 & 5.468 & 0.350 & 6.715 & 3.432 & 0.383 & 1.025 & 7.770 & 1.896 & 3.091 \\
\hline 12 & James Cook & 3.210 & 1.186 & 6.594 & 1.593 & 1.401 & 1.607 & 0.415 & 6.257 & 9.176 & 1.384 & 6.421 & 3.528 & 1.457 & 2.797 & 9.055 & 3.439 & 3.215 \\
\hline 13 & La Trobe & 2.045 & 1.296 & 5.669 & 0.782 & 1.677 & 1.141 & 1.035 & 6.436 & 8.424 & 0.985 & 5.819 & 2.794 & 1.072 & 2.201 & 7.848 & 3.232 & 2.217 \\
\hline 14 & Macquarie & 1.992 & 5.027 & 2.332 & 2.637 & 6.169 & 3.800 & 4.894 & 13.303 & 14.562 & 4.037 & 2.694 & 0.805 & 4.222 & 5.908 & 3.713 & 8.190 & 0.129 \\
\hline 15 & Melbourne & 9.162 & 18.094 & 1.494 & 15.399 & 21.132 & 15.949 & 18.813 & 32.846 & 35.085 & 17.829 & 1.590 & 3.552 & 18.116 & 21.771 & 0.943 & 25.261 & 4.735 \\
\hline 16 & Monash & 1.135 & 4.593 & 1.083 & 3.006 & 6.081 & 3.396 & 5.300 & 12.969 & 14.482 & 4.127 & 1.436 & 0.174 & 4.277 & 6.157 & 2.014 & 8.169 & 0.258 \\
\hline 17 & Murdoch & 1.997 & 4.647 & 1.192 & 3.489 & 5.998 & 3.871 & 4.587 & 13.498 & 15.817 & 4.462 & 1.235 & 0.149 & 4.624 & 6.780 & 2.409 & 8.678 & 0.286 \\
\hline 18 & New England & 2.807 & 6.226 & 3.199 & 3.091 & 7.298 & 4.761 & 5.849 & 14.663 & 15.501 & 4.809 & 3.668 & 1.517 & 5.020 & 6.590 & 4.665 & 9.182 & 0.407 \\
\hline 19 & New South Wales & 4.650 & 10.913 & 0.081 & 9.272 & 13.335 & 9.384 & 11.729 & 22.907 & 25.227 & 10.903 & 0.176 & 0.988 & 11.115 & 14.133 & 0.122 & 16.763 & 2.029 \\
\hline 20 & Newcastle & 0.000 & 2.720 & 3.595 & 1.391 & 3.995 & 1.330 & 4.890 & 8.135 & 8.429 & 2.076 & 4.455 & 2.082 & 2.141 & 3.090 & 4.461 & 4.561 & 2.079 \\
\hline 21 & Northern Territory & 2.720 & 0.000 & 9.190 & 1.195 & 0.159 & 0.363 & 0.874 & 2.414 & 4.513 & 0.381 & 9.414 & 5.837 & 0.356 & 0.981 & 11.423 & 0.932 & 5.859 \\
\hline 22 & Queensland & 3.595 & 9.190 & 0.000 & 7.629 & 11.407 & 7.763 & 9.982 & 20.384 & 22.579 & 9.119 & 0.136 & 0.515 & 9.316 & 12.098 & 0.238 & 14.565 & 1.380 \\
\hline 23 & Queensland Universit & 1.391 & 1.195 & 7.629 & 0.000 & 1.544 & 0.426 & 2.238 & 4.454 & 4.839 & 0.291 & 8.382 & 4.463 & 0.337 & 0.665 & 9.570 & 1.694 & 3.538 \\
\hline 24 & Royal Melbourne Inst & 3.995 & 0.159 & 11.407 & 1.544 & 0.000 & 0.788 & 0.682 & 1.764 & 3.973 & 0.528 & 11.575 & 7.494 & 0.491 & 0.913 & 14.009 & 0.647 & 7.269 \\
\hline 25 & South Australia & 1.330 & 0.363 & 7.763 & 0.426 & 0.788 & 0.000 & 1.857 & 3.125 & 4.148 & 0.153 & 8.362 & 4.771 & 0.150 & 0.600 & 9.593 & 1.071 & 4.535 \\
\hline 26 & Southern Cross & 4.890 & 0.874 & 9.982 & 2.238 & 0.682 & 1.857 & 0.000 & 4.319 & 7.621 & 1.413 & 9.694 & 6.193 & 1.436 & 2.485 & 12.875 & 2.484 & 5.910 \\
\hline 27 & Southern Queensland & 8.135 & 2.414 & 20.384 & 4.454 & 1.764 & 3.125 & 4.319 & 0.000 & 1.070 & 2.694 & 21.034 & 15.359 & 2.545 & 1.794 & 23.207 & 0.656 & 14.946 \\
\hline 28 & Sunshine Coast & 8.429 & 4.513 & 22.579 & 4.839 & 3.973 & 4.148 & 7.621 & 1.070 & 0.000 & 3.702 & 23.982 & 17.485 & 3.555 & 2.035 & 25.015 & 1.436 & 16.375 \\
\hline 29 & Swinburne University & 2.076 & 0.381 & 9.119 & 0.291 & 0.528 & 0.153 & 1.413 & 2.694 & 3.702 & 0.000 & 9.688 & 5.634 & 0.002 & 0.288 & 11.290 & 0.730 & 5.027 \\
\hline 30 & Sydney & 4.455 & 9.414 & 0.136 & 8.382 & 11.575 & 8.362 & 9.694 & 21.034 & 23.982 & 9.688 & 0.000 & 0.647 & 9.889 & 12.948 & 0.541 & 15.261 & 1.701 \\
\hline 31 & Tasmania & 2.082 & 5.837 & 0.515 & 4.463 & 7.494 & 4.771 & 6.193 & 15.359 & 17.485 & 5.634 & 0.647 & 0.000 & 5.805 & 8.111 & 1.363 & 10.216 & 0.359 \\
\hline 32 & University of Techno & 2.141 & 0.356 & 9.316 & 0.337 & 0.491 & 0.150 & 1.436 & 2.545 & 3.555 & 0.002 & 9.889 & 5.805 & 0.000 & 0.261 & 11.491 & 0.656 & 5.220 \\
\hline 33 & Victoria University & 3.090 & 0.981 & 12.098 & 0.665 & 0.913 & 0.600 & 2.485 & 1.794 & 2.035 & 0.288 & 12.948 & 8.111 & 0.261 & 0.000 & 14.372 & 0.299 & 7.175 \\
\hline 34 & Western Australia & 4.461 & 11.423 & 0.238 & 9.570 & 14.009 & 9.593 & 12.875 & 23.207 & 25.015 & 11.290 & 0.541 & 1.363 & 11.491 & 14.372 & 0.000 & 17.070 & 2.481 \\
\hline 35 & Western Sydney & 4.561 & 0.932 & 14.565 & 1.694 & 0.647 & 1.071 & 2.484 & 0.656 & 1.436 & 0.730 & 15.261 & 10.216 & 0.656 & 0.299 & 17.070 & 0.000 & 9.569 \\
\hline 36 & Wollongong & 2.079 & 5.859 & 1.380 & 3.538 & 7.269 & 4.535 & 5.910 & 14.946 & 16.375 & 5.027 & 1.701 & 0.359 & 5.220 & 7.175 & 2.481 & 9.569 & 0.000 \\
\hline
\end{tabular}

Source: The Authors' calculations using the normalised data 